Review Article

\title{
STEM Teacher Education and Professional Development and Training: Challenges and Trends
}

\author{
Aregamalage Sujeewa Vijayanthi Polgampala*, Hong Shen, Fang Huang \\ School of Education, Huazhong University of Science and Technology, Wuhan, China \\ Email address: \\ sujeewavijayanthi@yahoo.com (A. S. V. Polgampala) \\ ${ }^{*}$ Corresponding author
}

\section{To cite this article:}

Aregamalage Sujeewa Vijayanthi Polgampala, Hong Shen, Fang Huang. STEM Teacher Education and Professional Development and Training: Challenges and Trends. American Journal of Applied Psychology. Vol. 6, No. 5, 2017, pp. 93-97. doi: 10.11648/j.ajap.20170605.12

Received: June 21, 2017; Accepted: July 10, 2017; Published: October 18, 2017

\begin{abstract}
One of the four goals of STEM aims to educate the best STEM (Science, Technology, Engineering \& Mathematics) experts in the world. Professional Development programs shared the elements of strong leadership, Building capacity of teachers, and provide instructional guidance for them. However, STEM teachers encountered difficulties in adapting to the new integration reforms into their classrooms Therefore, high quality STEM infusion professional development programs are an urgent need. Hundred and sixty (160) research articles related to STEM from international journals overviewed that transforming from deeply rooted out dated approaches in teaching and embracing science through STEM is the panacea to excel $21^{\text {st }}$ Century Education Competencies. In the midst of discouraging circumstances findings unraveled that the trend of STEM augmentation is growing at a slow but steady pace in developing countries but it has led to an alarming trend in some developed countries in the world. By combing the related literature, this paper summarizes that an update of promising practices in STEM teacher education programs in enhancing student learning in their own context is a drastic need and highly-qualified STEM teachers are still in high demand.
\end{abstract}

Keywords: Professional Development, STEM Education, Teacher Training, $21^{\text {st }}$ Century Competencies, Trends \& Challengers

\section{Introduction}

Science is a constantly evolving field. Research on science education has attracted great attention in recent years. In order to apply innovative teaching strategies and advanced technique into classroom (McLaughlin \& Talbert, 2006), STEM is a new way to reach students, is not an entirely new phenomenon. There has been a dramatic increase in the number of STEM-focused schools in recent years. STEM infusion is the pipeline into which teachers become no longer of information distributors; this new approach will enable students to be responsible for their own learning (Gasiewski, Eagan, Garcia, Hurtado, \& Chang, 2012). To achieve this goal mastery or perfecting of pedagogy is necessary for educators' to manage their classroom and deliver effectively. STEM educators must be able to call on a repertoire of strategies and methods for illuminating STEM topics guiding students in scientific inquiry, the design of experiments get more teachers involved in STEM education by alleviating their fears. Focus on in-service programs and provision of specific training for subject knowledge, pedagogy, and classroom management to meet the teacher's current needs is a great importance. Marginalized perceived perceptions and teachers lacking strong efficacy are main obstacles to enhance STEM in developing countries (Mejia, 2011). STEM process skills can harness to meet the challenges of 21 st century globally. In the first, theoretical section of this paper, we argue that some consider STEM education to be the improved teaching of the separate subjects of STEM others believe STEM should be taught in an integrative subjects approach. Majority believe it is a combination of both of these approaches. If this is the case what aspects should be considered in the professional development or training programmes and how congruent changes bring forth towards reformed pedagogical beliefs for the majority of participants (Tatto \& Coupland, 2003). This paper also reviews these factors, presents several aspects of 
teacher education programs that have been effective, and makes specific recommendations for improving the quality of teaching and provides guidelines for improving the professional development of teachers for a congruent change toward reformed pedagogical. These guidelines furnish a range of alternatives that have been tried in STEM systems imposing the needs of a globalized world of the 21 st century on Professional development and efficacy elicits in educators develop new instructional techniques, recruit highly-qualified passionate science teachers, provide opportunities for extracurricular activities, and foster connections with the professional community.

\section{The Purpose of the Study}

Qualified teachers are essential to STEM teaching and professional development is a great need to cultivate knowledge content as well as pedagogical knowledge ability. This study is to identify the related literature on professional development programmes and to find out the opportunities, trends and challengers. Specifically, the study shall be investigating the following:

i. How teacher education and professional development and training in STEM can make an impact on student achievement in STEM

ii. The role of STEM teacher and how can best be prepared for teaching STEM in the 21st century

iii. Issues, implications, and challenges of globalization through STEM education

iv. How STEM training programmes focus on real-world issues and problems

Teachers need to be actively involved in the changing process of STEM education and update and upgrade through professional training programmes. In order to incorporate the demanding characteristics of professional development programs, this study aimed to explore related literature to find solutions to the above issues.

\section{Literature Survey}

A prime goal of STEM educational reform is to encourage a shift from teacher centered classrooms where students are passive consumers to student-centered environments where learning is an active process (Smith, Vinson, Smith, Lewin, \& Stetzer, 2014) The NMC Horizon Report: 2015 K-12 Edition examined emerging technologies for their potential impact on and use in teaching, learning, and creative inquiry in schools (Johnson, Levine, Smith, \& Stone, 2010) boost student interest highly and keep them in the STEM pipeline. But none of these solutions had proven to be a silver bullet and that could be frustrating (Most, 1996). Teacher effectiveness is usually expressed in terms of pupils' academic achievement hence educators' active participation strive students to get excited on STEM disciplines through various activities, including hands-on activities (Ejiwale, 2012). Successful shifting of the pedagogical beliefs of teachers toward a reformed mindset is essential if professional development is to positively influence teaching in STEM classrooms (Crowther, Ferguson, \& Hann, 2009). STEM educators, with a new paradigm shift as "facilitators" and laboratories well-equipped with modules where students will spend most of their time learning, will help students to take what they learn in the classroom and laboratory and apply it to future jobs in the real world (Salmi, 2014). These practical applications of the concepts students learn in the classroom and laboratory will help enhance the quality of STEM education (Darling-Hammond, 1994; Ejiwale, 2012, 2013) Olawoye, 2010). Creative problem solving, product building, collaborative team work, design, and critical thinking (Aleman, 1992; (Darling-Hammond, 1996) are mandatory skills that are addressed in STEM programs in order to build a culture of interest in science to enabl to gap the bridge educators are to facilitate STEM activities of students with reduced input to solutions needed to problem solve or to do hands-on activities (Tytler, Symington, \& Smith, 2011). Aleman (1992) described this further: "It is no longer acceptable for the teacher to be the one with the knowledge (Alemán, López, \& Solís). Teachers must become comfortable with students as their own teachers working in cooperative groups to solve problems in a culturally, technologically, and socially evolving environment. "Natural curiosity of students that will lead them to bodies of knowledge and means of discovery that teachers can encourage." (p. 97) (N. A. Glasgow, 1997). There is a need for investing in the preparation of the potential STEM educator so he or she will be well equipped with the skills necessary to navigate successfully in this new mindset. Researchers (Tschannen-Moran \& Woolfolk Hoy, 2002) defined educator efficacy as an educator's judgment of his/her capabilities to bring about desired outcomes of student engagement and learning, even among those students who may be difficult or unmotivated. This makes learners more active during the learning process through active participation (R. E. Glasgow et al., 1997; Pullias, 1994). Since facilitative teaching is not an art innate in teachers (Wittmer 1980), STEM educators must learn this skill. Learning is fostered when there is active facilitation of students' activities and their interactions between with peer learners. Teaching in STEM environment requires competency in pedagogy that ensures active participation in classroom activities by learners. More importantly, educator's efforts should be geared towards meaningful teaching and learning through practical illustrations and applications (DeJarnette, 2012; Sublette, 2013). The most common elements of effective teaching have been excerpted from (Heneveld \& Craig, 1996) which deals specifically with applying factors of school effectiveness and improvement to educational project design. Twenty First Century Science courses developed at the University of York focus of courses for 14- to 16-year-olds is of students as 'consumers not producers of science' (Millar, 2006). If teachers are confident and supported in implementing such an approach, young people will be more engaged.

\section{Methodology}

One way to gain insight into an uncertain future is to 
construct scenarios. This study searched journal articles by key words including professional development, Teacher training, STEM classroom, 21 centaury competencies, technology enhanced classroom, blended learning opportunities, transmission to transforming ,key barriers ,future opportunities related to STEM. Finally 160 journal articles related to STEM were selected from digital databases including STEM journals, EBSCO host ,Web of Science, Emerald, ERIC, SciEP and Scopus for were selected for content analysis. We analyzed the papers as two types of items. One was the basic information of each paper, including its title, date of publish, name of journal, author, The other was content analysis of the paper, including its research purpose, research settings, research environment, research issues, findings, conclusions, teaching and learning activities, approaches, trends and challenge on STEM related to scenario. Through the review of current researches, the study aimed to find the research trend and the driving force of researches on professional development of teachers in STEM pipeline.

\section{Findings}

This study focused on literature survey of STEM education in to address the competencies in $21^{\text {st }}$ century as well as the challenges and trends in facing its integration into a globalized world. The study found that STEM has been a worldwide research area with distinctive regional characteristics in its research issues. Pedagogical contentment STEM have been studied the most, and future classroom environment, the innovation of teaching and learning activities with support of information technologies, and the learning experience of teacher and student have become the hot issues. The most conclusions of the publications showed that the teachers' roles, students' performance, and trend towards STEM were positive. These technologies make the learning environment more flexible and adaptable, as well as enable more effective individual and social learning processes. The main obstacles found were teachers perceived perceptions and phobia for technology, especially among females. What Ozigi (1977) said is true in STEM too unlike in the other discipline, all the Science teachers were expected to possess concurrently two competences: (1) Technical (2) Personal competency. Nwachukwu (2000) argued that, regardless of the country concerned, the problems identical and each should endeavor to solve any problems identified immediately or as the need arises.

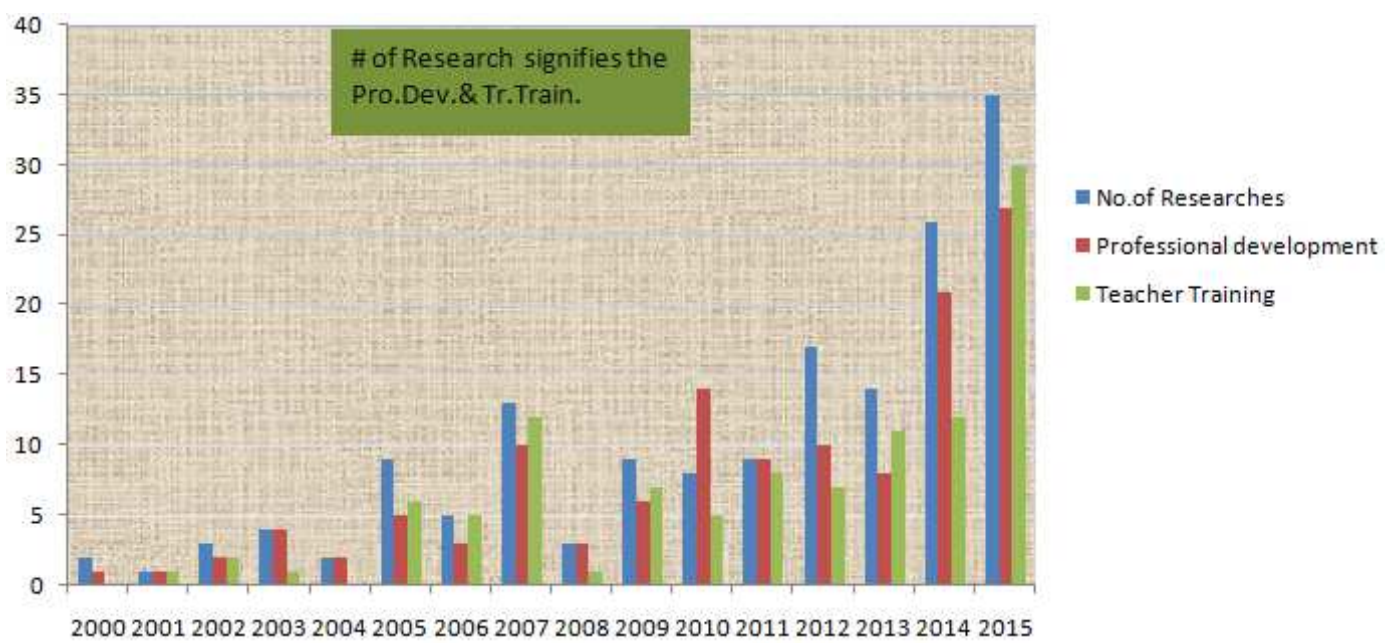

Figure 1. \# of research signifies the Prof. Dev.\& Tr. Train in STEM.

The graph above illustrates that the trend towords STEM researched has been incresasing over the last fifteen years and the beginning of the millenium showd less focus on STEM professional development and teacher training compared to the resent years. Almost all articles discussed importance of traininng of teachrs.

Table 1. STEM Research vs. Area.

\begin{tabular}{llll}
\hline Area & \# of Research on STEM & Area & \# of Research on STEM \\
\hline Australia & 21 & India & 4 \\
USA & 54 & Bangaladesh & 1 \\
UK & 12 & Japan & 5 \\
Philipenes & 7 & Malawi & 1 \\
Mainland China & 19 & Newzealand & 6 \\
Sri Lanka & 4 & South Korea & 7 \\
Taiwan & 3 & Hongkong & 5 \\
Canada & 7 & & \\
\hline
\end{tabular}

The table depicts from the distribution of 160 research from different areas in the world, USA, Australia, Mainland China are still in the top list among the countries who focus special attention on to the new trend of infusion of STEM. Researches revealed that qualified teachers were essential to STEM teaching and professional development was necessary to 
cultivate content knowledge as well as pedagogical knowledge is a current challenge in most of developing countries. Teachers with a strong capacity to teach in their discipline were essential for the success of any STEM programme. Staff development through seminars, In-service training or workshops offers a promising future for STEM. These highly-qualified STEM teachers are in high demand, as they are the pioneers in stimulate students' interests towards subjects. They lack coordination and coherence in these programmes were also identified in the study.

\section{Results and Discussion}

Professional development for teachers and proper training in STEM education is the driving force of STEM education. Especially, eradicating teachers misbelieves and phobia for the use of technology which were the main barriers. However, the research revealed that there were also some specific problems to be solved at the STEM classrooms too, including poor software compatibility and internet facilities. A great significance for the design of future STEM classrooms and use of active learning spaces is an essential factor for better future for STEM. To suggest further expounding the design theories of learning spaces and illuminate the design of future classrooms with the rapid development of education through STEM, future classroom, innovative learning space are products of the educational reform and also "team teaching which allows for content specialization" is one of the factors resulting in training programmes. The study summarizes both advantages and disadvantages STEM classes and essential skills the teachers need to develop and put forward some suggestions for improvement to meet the learners' needs. Comprehensive review of literature analyzes and outlines the basic features which should be equipped by future classrooms, taking successfully future classrooms for example. Finally, researchers propose several dimensions for future classroom's construction as references for follow up research.

\section{Conclusion}

Teacher development plan should be thought of as an ongoing participatory process tied to learning needs of children. Teacher development can make a difference to student achievement, but it depends on the type of education program and support that is put in place. Many key factors can contribute to improving a teacher's performance and hence student achievement. STEM educational blueprint was paramount whatever innovative approaches were put into place, integrating Professional development for STEM teachers should persist over an extended period of time. Surveys of teachers suggest that teachers were most interested in STEM-focused professional development that emphasized career awareness, inquiry based activities, and interdisciplinary activities. Visits and tours or workshop activities were the most preferred modes of delivery. There is a need to increase awareness among parents and students concerning the importance of STEM education. The following three messages are most likely to resonate positively with the community: (1) STEM education prepares all students for the challenges and opportunities in the 21 st century economy (2) STEM education improves the impact and overall effectiveness of the K-16 education system; and (3) A STEM-literate workforce adds value, productivity, and innovations to the economy. Technology into the daily educational experience specially trained STEM teachers who knew how to best present these subjects, inquiry-based interactive teaching methodologies and to robust curriculum with adequate knowledge assessment practices is a still a great demand. Policymakers and professionals emphasize STEM education by legislating engineering standards to the existing science standards

\section{Limitations}

It is presumptuous to attempt to cover all aspects of teaching and teacher education in STEM worldwide in one review through a literature survey of 160 research on STEM and we continuously found ourselves having to limit our work, due to time constraints, and the multiple scenarios of teacher development programmes.

\section{Recommendations}

STEM teachers have to develop innovative approaches through blended learning. Continuous Capacity Building of teachers is an urgent need. There is no single best way to prepare and support teachers, so alternatives that had been effective in different contexts. Many challenges can be envisaged, Researches are needed to find out re-imagining in science for future through infusion of STEM since it literate workforce adds value, productivity, and innovations to the economy: STEM-literate workers create a culture of innovation in business and are important contributors to economic development.

\section{References}

[1] Crowther, Frank, Ferguson, Margaret, \& Hann, Leonne. (2009). Developing teacher leaders: How teacher leadership enhances school success: Corwin Press.

[2] Darling-Hammond, Linda. (1994). Performance-based assessment and educational equity. Harvard Educational Review, 64 (1), 5-31.

[3] Darling-Hammond, Linda. (1996). The right to learn and the advancement of teaching: Research, policy, and practice for democratic education. Educational Researcher, 25 (6), 5-17.

[4] DeJarnette, Nancy. (2012). America's children: Providing early exposure to STEM (science, technology, engineering and math) initiatives. Education, 133 (1), 77-84.

[5] Ejiwale, James A. (2012). Facilitating teaching and learning across STEM fields. Journal of STEM Education: Innovations and Research, 13 (3), 87. 
[6] Ejiwale, James A. (2013). Barriers to successful implementation of STEM education. Journal of Education and Learning (EduLearn), 7 (2), 63-74.

[7] Gasiewski, Josephine A, Eagan, M Kevin, Garcia, Gina A, Hurtado, Sylvia, \& Chang, Mitchell J. (2012). From gatekeeping to engagement: A multicontextual, mixed method study of student academic engagement in introductory STEM courses. Research in higher education, 53 (2), 229-261.

[8] Glasgow, Neal A. (1997). New Curriculum for New Times: A Guide to Student-Centered, Problem-Based Learning: ERIC.

[9] Glasgow, Russell E, La Chance, Pierre-Andre, Toobert, Deborah J, Brown, Jane, Hampson, Sarah E, \& Riddle, Matthew C. (1997). Long term effects and costs of brief behavioural dietary intervention for patients with diabetes delivered from the medical office. Patient education and counseling, 32 (3), 175-184.

[10] Heneveld, Ward, \& Craig, Helen. (1996). Schools count: World Bank project designs and the quality of primary education in Sub-Saharan Africa (Vol. 303): World Bank Publications.

[11] Johnson, Larry, Levine, Alan, Smith, Rachel, \& Stone, Sonja. (2010). The 2010 Horizon Report: ERIC.

[12] McLaughlin, Milbrey Wallin, \& Talbert, Joan E. (2006). Building school-based teacher learning communities: Professional strategies to improve student achievement (Vol. 45): Teachers College Press.

[13] Mejia, Brenda Xiomara. (2011). Perceived Career Barriers: The Role of Ethnic Identity, Acculturation, and Self-Efficacy Mediators among Latinalo College Students. Columbia University.
[14] Millar, Robin. (2006). Twenty first century science: Insights from the design and implementation of a scientific literacy approach in school science. International Journal of Science Education, 28 (13), 1499-1521.

[15] Pullias, D. (1994). New technology education programs and levels of learning experiences. The Technology Teacher, 53 (8), $5-6$.

[16] Salmi, Hannu. (2014). Bridging the Gap between Formal Education and Informal Learning via Science Centre Pedagogy. Paper presented at the International AEMASE Conference on Scienec Education Conference Report.

[17] Smith, Michelle K, Vinson, Erin L, Smith, Jeremy A, Lewin, Justin D, \& Stetzer, MacKenzie R. (2014). A campus-wide study of STEM courses: new perspectives on teaching practices and perceptions. CBE-Life Sciences Education, 13 (4), 624-635.

[18] Sublette, Heidi. (2013). An effective model of developing teacher leaders in STEM education: Pepperdine University.

[19] Tatto, Maria Teresa, \& Coupland, Daniel Bryan. (2003). Teacher education and teachers' beliefs. Teacher beliefs and classroom performance: The impact of teacher education, 123-184.

[20] Tschannen-Moran, Megan, \& Woolfolk Hoy, Anita. (2002). The influence of resources and support on teachers' efficacy beliefs. Paper presented at the annual meeting of the American Educational Research Association, New Orleans, LA.

[21] Tytler, Russell, Symington, David, \& Smith, Craig. (2011). A curriculum innovation framework for science, technology and mathematics education. Research in science education, 41 (1), 19-38. 